\title{
Experience of Cancer Patients for the Usage of Complementary and Alternative Medicine Therapy
}

\author{
Zafar Rasheed ${ }^{1 *}$, Mohammed Al-Rashidy², Anas Al-Raqibah², Abdulrahman Al-Moqbel ${ }^{2}$, Abdulmajeed Al-Bakri ${ }^{2}$, \\ Abdulaziz Al-Harbi ${ }^{2}$, Naila Rasheed ${ }^{1}$, Waleed Al Abdulmonem ${ }^{3}$ \\ ${ }^{1}$ Department of Medical Biochemistry, College of Medicine, Qassim University, Buraidah, Saudi Arabia; ${ }^{2}$ Research Center, \\ College of Medicine, Qassim University, Buraidah, Saudi Arabia; ${ }^{3}$ Department of Pathology, College of Medicine, Qassim \\ University, Buraidah, Saudi Arabia
}

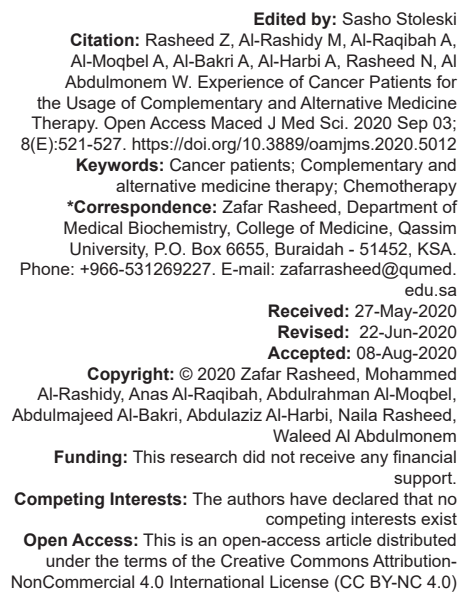
Edited by: Sasho Stolesk
Citation: Rasheed Z, Al-Rashidy M, Al-Raqibah A Citation: Rasheed Z, Al-Rashidy M, Al-Ragibah A,
Al-Mogbel A, Al-Bakri A, Al-Harbi A, Rasheed N, Al Abdulmonem W. Experience of Cancer Patients for the Usage of Complementary and Alternative Medicine Therapy. Open Access Maced J Med Sci. 2020 Sep 03 Therapy. Open Access Maced J Med Sci. 2020 Sep 03
8(E):521-527. https://doi.org/10.3889/oamjms.2020.5012 Keywords: Cancer patients; Complementary and alternative medicine therapy; Chemotherapy *Correspondence: Zafar Rasheed, Department of Medical Biochemistry, College of Medicine, Qassim University, P.O. Box 6655, Buraidah - 51452, KSA Phone: +966-531269227. E-mail: zafarrasheed@qumed. Received: 27-May-2020 Revised: 22-Jun-2020 Accepted: 08-Aug-2020 Copyright: $\odot 2020$ Zafar Rasheed, Mohammed Al-Rashidy, Anas Al-Raqibah, Abdulrahman Al-Moqbel, Abdulmajeed Al-Bakri, Abdulaziz Al-Harbi, Naila Rasheed, Waleed Al Abdulmonem

Funding: This research did not receive any financial Competing Interests: The authors have declared that no competing interests exis Open Access: This is an open-access article distributed NonCommercial 4.0 International License (CC BY-NC 4.0)

\begin{abstract}
BACKGROUND: Cancer patients have always been reported to have multiple complications and the treatment has always seemed challenging. The complementary and alternative medicine (CAM) therapy has widely accepted by the patients with various disorders.

AIM: This study evaluated the experience of cancer patients for the usage of CAM therapy.

MATERIALS AND METHODS: This is a cross-sectional study designed to determine the experience of cancer patients for the usage of CAM therapy.

RESULTS: Out of 232 cancer patients, $94 \%$ were urban residents and were non-smokers. Importantly, $66.4 \%$ of cancer patients experienced that the combination of CAM with conventional chemotherapy was effective for their treatment. Among all CAM therapies, 31.5\% cancer patients experienced that herbal medicines/herbs were good Among herbal therapies, green tea and black seeds were most effective for cancer patients. In contrast, $12.5 \%$ patients experienced that homeopathic medicines were good for their treatment.

CONCLUSIONS: To the best of our knowledge, this is the first comprehensive study from Saudi Arabia to show the experience of cancer patients toward the usage of CAM therapy. Most of the cancer patients experienced that CAM therapies with the convention chemotherapy were effective for their treatment. Among all studied CAM therapies, green tea and black seeds were suggested by most of the cancer patients for their treatment.
\end{abstract}

\section{Introduction}

It is now well documented that cancer is one of most prevalent disorders associated with the maximum death globally in all countries regardless of their income levels [1], [2], [3]. Decades by decades, the occurrence of cancer patients is continuously increasing and its management seems to be difficult [1], [2], [3], [4]. Reports have shown that more cancer patients are found in high-income countries as compared to the prevalence rate in low-income countries [2]. And reason is the people adopt easy lifestyle that may increase the risk of cancer onset. However, there are many countries they have taken lots of steps in controlling the prevalence of cancer and they got successes by controlling the use of tobaccos, vaccination of anti-cancer drugs, and promotion programs on the early detection of cancer [3], [4]. Recently, Torre et al. had extensively reviewed the global prevalence of cancer occurrence in low- and high-income countries [1], [2], [3].
In Saudi Arabia, several studies were conducted on the epidemiology of cancer [5], [6]. The majority of the reports pointed out that the rate of cancer occurrence is increasing since 1994 and it is on the rise [5]. Recently, Bazarbashi et al. reported the data of Saudi Cancer Registry (SCR) showing that the prevalence of cancer onset is on the rise and Riyadh was on the top of the list [5]. They also have made gender characterization of cancer patients and reported that males were having high prevalence rate of cancers with colorectal, non-Hodgkin lymphoma, leukemia, live, lung, prostate, Hodgkin, bladder, thyroid, and kidney with the highest prevalence [5]. Whereas the females reported to have highest cancer prevalence with breast, thyroid, colorectal, non-Hodgkin lymphoma, corpus uteri, ovary, Hodgkin, cervix uteri, and liver [5]. Despite of all major steps taken by the Ministry of Health of Saudi Arabia, still the management of cancer seems to be difficult and the rate of occurrence is on the rise [7]. Global reports on cancer patients have always shown that the cancer patients are associated with multiple complications and the treatment of them is always challenging [1], [8]. 
Despite of the advancement of modern techniques or surgical approaches, the treatment of cancer patients is still seems to be difficult and the success rate in the current scenario is $<60 \%$ and most importantly, the treatment is associated with multiple side effects and sometimes these side effects become a cause of their death [2], [8].

In recent years, the usage of complementary and alternative medicine (CAM) as a therapy for numerous disorders by the world population has tremendously increased and now the population from all over the world likes to use CAM therapy before the start of the modern allopathic or modern treatment [9], [10], [11]. As the treatment with CAM has no sideeffects [12], [13], [14], [15]. As far as, the treatment of cancer patients is concern with the modern medicines or chemotherapy, which is highly associated with the horrified side effects; therefore, CAM therapy for cancer patients has becomes the first choice their treatment [16], [17], [18], [19]. A lots of survey based studied have concluded that CAM therapies are very famous among cancer patients in both low- and high-income countries [10], [11], [12]. Most favorable CAM therapies among cancer patients were found to be dietary treatments, homeopathy, herbal therapy, green tea consumption, massage, and so on [10], [11], [12].

In view of these, this study is hypothesized that the cancer patients visiting in the hospitals of Qassim region of KSA are likely in use of CAM therapies. To prove this hypothesis, a self-administrated questionnaire was distributed to the cancer patients visiting in the designated hospital. This questionnaire comprised three different sections, the first section was composed of simple questions on personal and clinical information of the cancer patients, whereas second part composed of question on their knowledge and experience of the usage of CAM therapies and the third part of this questionnaire was composed of questions related to their attitude toward the usage of CAM therapies. Through this study, we got to know the status of CAM therapies in their disease associated life and we also investigated the most popular CAM therapies among them.

\section{Methods}

\section{data collection \\ Study type, design, human subjects, and}

This is a retrospective cohort study designed to determine the knowledge, awareness, and attitude of cancer patients for the usage of CAM therapy using a self-administrated questionnaire, which was re-validated from the similar studies reported as described previously [10], [14]. This study was performed in accordance with the Code of Ethics of the World Medical Association
(Declaration of Helsinki as revised in Tokyo, 2004) for humans during September 2019-February 2020. The study protocol was approved by the Ethical Committee of Qassim University (CL-2019061702), with the approval of review board, cancer patients $(n=232)$ were involved, who were attended cancer outpatients clinics at regional hospitals of Qassim, KSA from September 2019-February 2020. The data were collected by interviewing the patients using the same questionnaire described above. Briefly, the questionnaire was comprised three different sections, first section was about the simple questions on personal and clinical information, second section was composed of questions on their knowledge and experience of the usage of CAM therapies and the third section of this questionnaire was about the questions related to their attitude toward the usage of CAM therapies.

\section{Statistical analysis}

The frequencies of distributed proportions were calculated by statistical data software (SPSS, IBM, TX, USA) using a Chi-square test and results were further validated using the Prism GraphPad (San Diego, CA, USA).

\section{Results}

\section{subjects}

Social and demographic details of studied

Out of 232 cancer patients visiting in hospitals of Qassim region, $54.3 \%$ were females whereas $45.7 \%$ were males. The majority of participants was urban residents (94\%) and was non-smokers (85.3\%). The body mass index (BMI) results showed that $19.4 \%$ of participants were underweight, whereas $50.5 \%$ were obese. The complete details of social and demographic, including the status of their educational level and their living and residential standards, are summarized in Table 1.

Table 1: Social and demographic details of the studied subjects

\begin{tabular}{lll}
\hline Characteristics of studied subjects & Number of participants (n=232) & Percentage \\
\hline Gender & & \\
$\quad$ Male & 106 & 45.7 \\
$\quad$ Female & 126 & 54.3 \\
Age (years) & & \\
$\quad$ 18-35 & 62 & 27.5 \\
$\quad>35$ & 170 & 72.5 \\
Marital status & & \\
$\quad$ Single & 106 & 45.7 \\
$\quad$ Married & 126 & 54.3 \\
Smoking history & & \\
$\quad$ Smokers & 34 & 14.7 \\
$\quad$ Non-smokers & 198 & 85.3 \\
Educational level & & \\
$\quad$ Primary or less & 16 & 6.9 \\
$\quad$ Secondary/high school & 84 & 36.2 \\
$\quad$ University or above & 132 & 56.9 \\
Living standard & & \\
$\quad$ Poor>5000 SAR & 74 & 31.9 \\
$\quad$ Average 5000-15,000 SAR & 96 & 41.4 \\
$\quad$ Good<15,000 & 62 & 26.7 \\
\hline
\end{tabular}




\section{Clinical details of studied cancer subjects}

This study included 232 cancer patients of different types. The majority of them were having cancer in the gastrointestinal tract, followed by breast cancer, cancer in the respiratory system and urinary system. Importantly, the results also pointed out that the majority of studied cancer patients $(77.6 \%)$ were having their family history of the same cancer types. The complete details of cancer patients with the cancer locations are summarized in Table 2.

Table 2: Location of cancers in the studied subjects

\begin{tabular}{lll}
\hline Cancer location & Number of cancer patients & Percentage \\
\hline GIT & 62 & 26.7 \\
Breast cancer & 54 & 23.3 \\
Respiratory system & 30 & 12.9 \\
Urinary system & 10 & 4.3 \\
Others & 76 & 32.8 \\
\hline GIT: Gastrointestinal tract. & &
\end{tabular}

Knowledge, attitude, and experience of cancer patients for the usage of CAM therapies by cancer patients

We analyzed the cancer patient's knowledge, attitude, and experience by multiple questions about CAM. Question on the source of CAM knowledge showed that 144 studied cancer patients $(62.1 \%)$ gained their CAM knowledge from their family members, whereas 88 patients $(37.9 \%)$ gained their CAM knowledge from other sources including books, advertisements, and internet. (Figure 1a). Interestingly, we also noticed that $81.9 \%$ of cancer patients $(n=190)$ were advised for taking CAM by the treating oncologists, whereas the rest $18.1 \%$ patients $(n=42)$ were not suggested for CAM by them (Figure 1b). Our data also showed that out of 232 studied cancer patients, 150 patients (64.6\%) showed interest in using CAM, whereas the rest 82 patients (35.4\%) showed no interest in CAM (Figure 1c). Importantly, the majority of cancer patients $(66.37 \%, \mathrm{n}$ $=154$ ) experienced that CAM therapy in combination with the conventional chemotherapy was effective in the treatment, whereas $12.93 \%(n=30)$ cancer patients experienced that CAM alone was good for the cancer treatment. Moreover, the rest $20.68 \%(n=48)$ cancer patients experienced that chemotherapy without CAM was good for them (Figure 1d). Not only have these but we also analyzed the experience of cancer patients toward the side effects of CAM therapy. As shown in Figure 1e, $47.4 \%(n=110)$ cancer patients experienced that CAM therapy has no side effects, whereas 35.5 $\%(n=80)$ patients realized that CAM has some side effects. However, $12.9 \%(n=30)$ patients have no idea for CAM therapy side effects. Figure $2 a$ summarizes the experience of cancer patients for the usage of different CAM therapies, $31.5 \%$ cancer patients experienced that herbal medicines/herbs were good for them as cancer therapy. Whereas $27.2 \%$ cancer patients experienced that different CAM in combined form were good for their treatment, followed by $12.5 \%$ patients liked

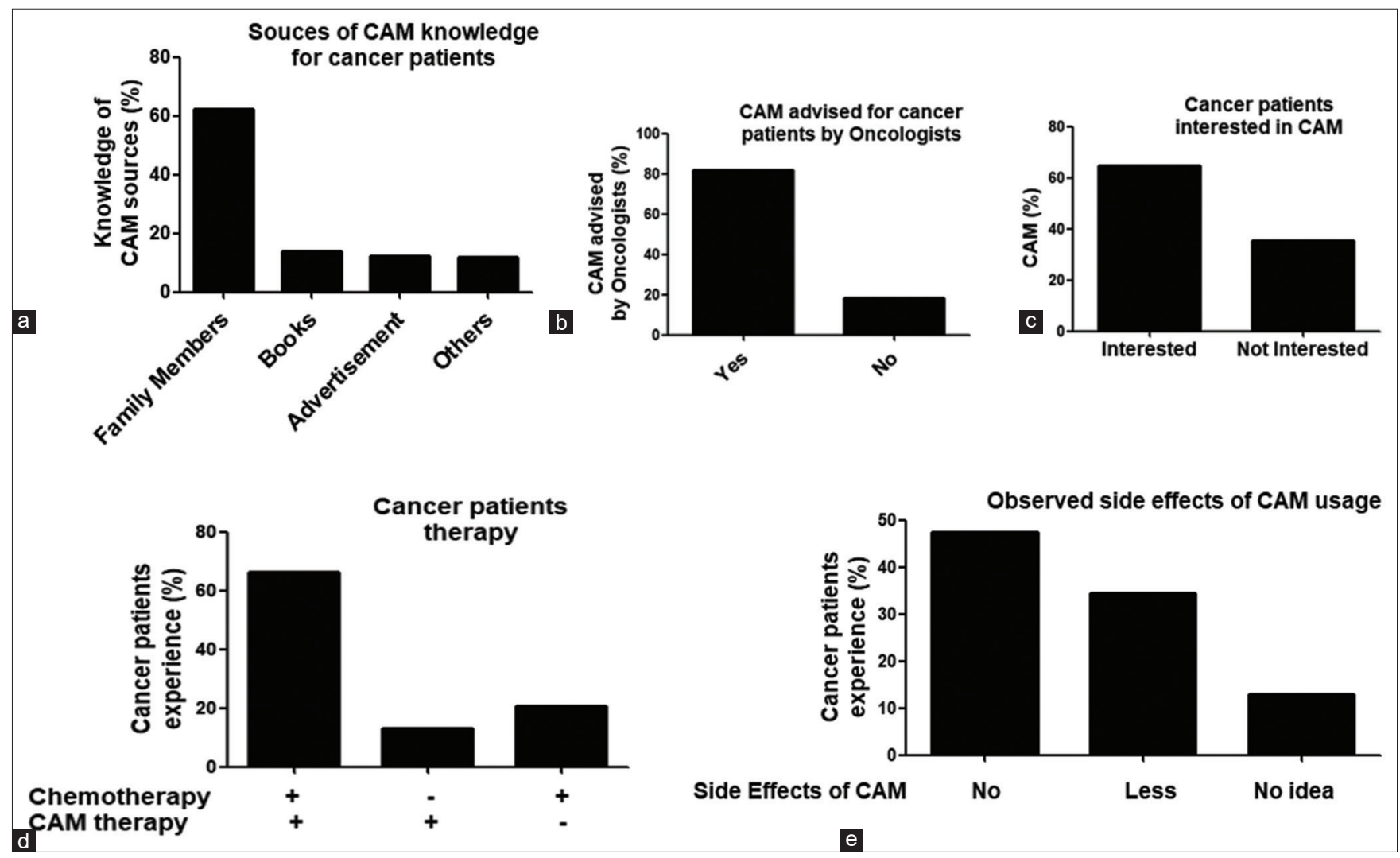

Figure 1: Knowledge and attitude of cancer patients for complementary and alternative medicine (CAM) therapies. (a) Sources of CAM knowledge for cancer patients. (b) The CAM advised by oncologist for cancer patients. (c) Interest of cancer patients in the CAM therapy. (d) Experience of cancer patients with the CAM therapy in combination with conventional chemotherapy. (e) Experience of cancer patients with side effects of CAM therapy in combination with the conventional chemotherapy 


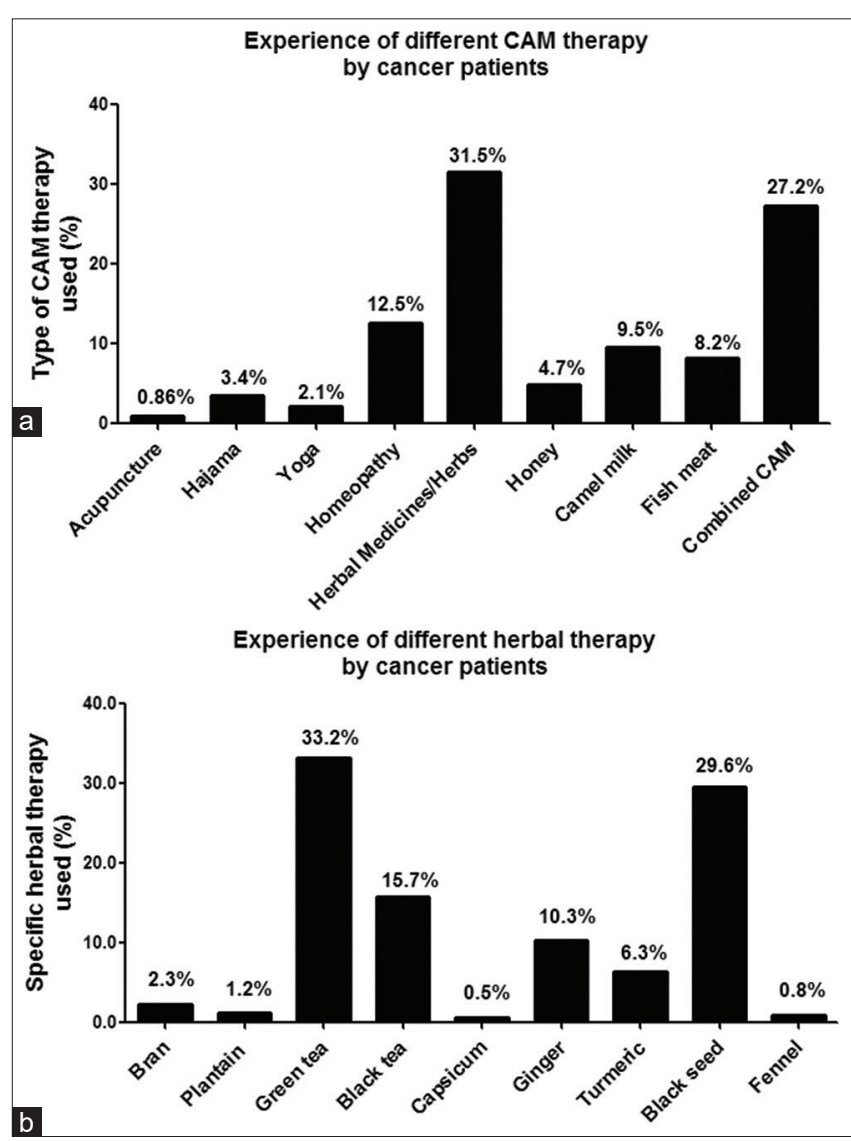

Figure 2: Experience of cancer patients for complementary and alternative medicine (CAM) therapies. (a) Experience of different CAM therapies by the cancer patients. (b) Experience of different herbal therapies by the cancer patients

homeopathic medicine for their treatment. To study the data of herbal therapy in depth, experience of cancer patients was analyzed for several herbal therapies such as bran, plantain, green tea, black tea, capsicum, ginger, turmeric, black seeds, and fennel (Figure 2b). Out of these herbal therapies, green tea and black seeds were found to be the favorable choice of cancer patients. The $33.2 \%$ cancer patient's experienced drinking green tea was good for their treatment, whereas, $29.6 \%$ patients believed that eating black seeds were good for their health. The description of other herbal products used by the cancer patients is given in Figure $2 \mathrm{~b}$. The complete CAM therapies used by the studied cancer patients are summarized in a flow chart diagram (Figure 3).

\section{Discussion}

To the best of our knowledge, this is the first comprehensive study from the central region of Saudi Arabia to show the relationship between the CAM and cancer patients. It is now well documented that the prevalence of cancer among all type of populations is continuously increasing and its management seems to be difficult [20]. Studies from all over the globe have

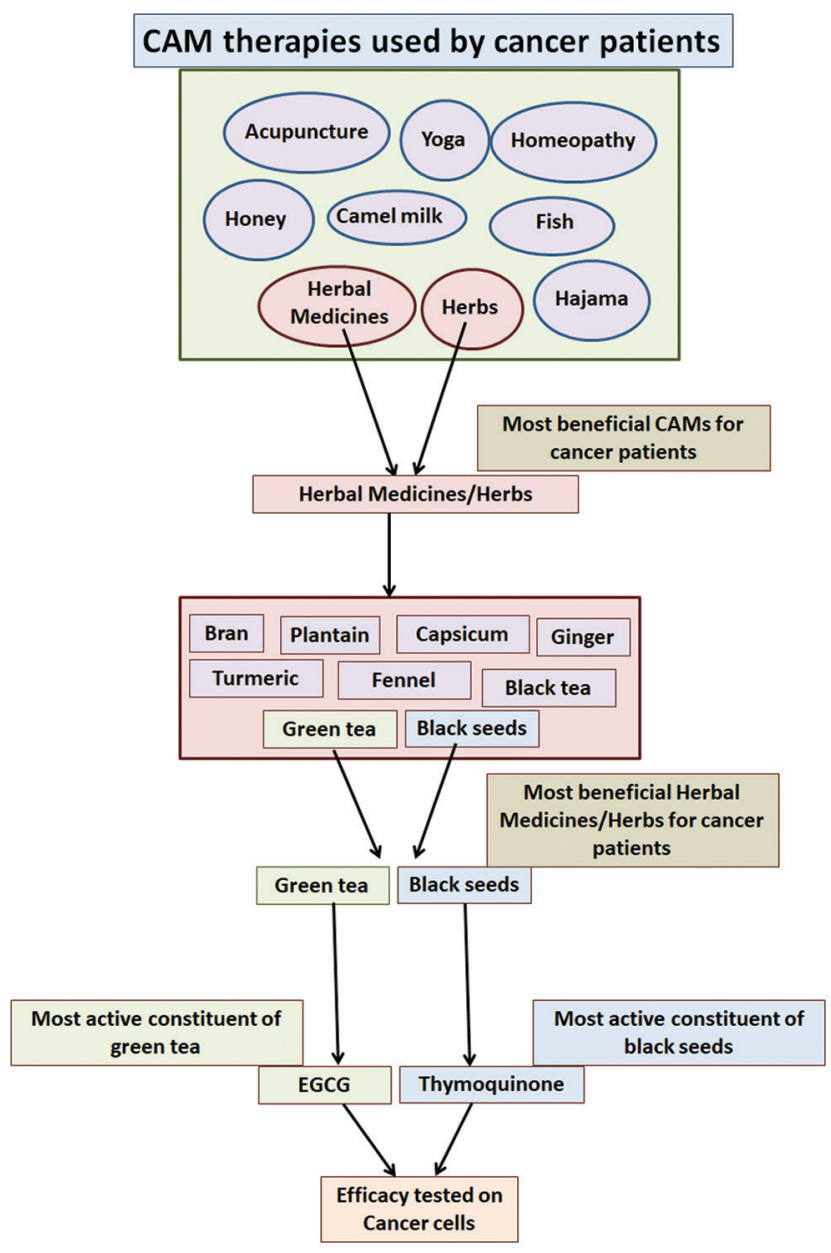

Figure 3: Flow chart describes the complementary and alternative medicine therapies used by the cancer patients

shown that more cancer patients are found in highincome countries as compared with the low-income countries [21]. This may be due to the adaptation of easy lifestyle that could proliferate the risk of cancer prevalence. However, there are many countries they have taken lots of steps in controlling the cancer onset and they got successes by promotion of anticancer awareness programs [22]. In Saudi Arabia, several studies were conducted on the epidemiology of cancer [5], [23]. The majority of the reports pointed out that the rate of cancer occurrence is increasing since 1994 and it is on the rise [5], [6], [23]. Recently, the data from the SCR showing that the prevalence of cancer onset is on the rise and Riyadh was on the top of the list [5]. They also have made gender characterization of cancer patients and reported that males were having high prevalence rate of cancers with colorectal, nonHodgkin lymphoma, leukemia, live, lung, prostate, Hodgkin, bladder, thyroid, and kidney with the highest prevalence [5]. Whereas the females reported to have highest cancer prevalence with breast, thyroid, colorectal, non-Hodgkin lymphoma, corpus uteri, ovary, Hodgkin, cervix uteri, and liver [5]. Despite of all major steps taken by the Ministry of Health of Saudi Arabia, still the management of cancer seems to be difficult and the rate of occurrence is on the rise [7], [23]. Global reports 
on cancer patients have always shown that the cancer patients are associated with multiple complications and the treatment of them is always challenging [24]. Despite of the advancement of modern techniques or surgical approaches, the treatment of cancer patients are still seems to be difficult and the success rate in the current scenario is less and most importantly, the treatment is associated with multiple side effects and sometimes these side effects become a cause of their death [24], [25]. Studies from the past three decades showed that the interest of cancer patients has continuously been increasing in CAM therapy in all over the globe [26]. This may be due to the continuous failure for the treatment of cancer patients with conventional therapies. It is now well established that CAM therapies are very famous among cancer patients in both lowand high-income countries [10], [11], [12]. Not only for cancer therapy, CAM and their associated products are also in use as an additional therapy for the treatment of various other chronic disorders [27], [28], [29].

We and the others have shown that the active constituents of different CAM products have shown anti-disease activity including the activity against cancer [30], [31], [32], [33], [34], [35], [36], [37], [38], [39], [40]. In this study, we have collected information from almost all types of cancer patients visiting in the hospitals of Qassim region about the usage of CAM therapies. The information was collected by a self-administrated questionnaire. This questionnaire comprised three different sections, the first section was composed of simple questions on personal and clinical information of the cancer patients, whereas second part composed of question on their knowledge and experience of the usage of CAM therapies and the third part of this questionnaire was composed of questions related to their attitude toward the usage of CAM therapies. Our data showed that out of 232 studied cancer patients, 150 patients showed interest in using CAM, whereas the rest 82 patients showed no interest in CAM. Moreover, the data also pointed out that the majority of cancer patients experienced that CAM therapy in combination with chemotherapy was good. These results are fully supported by other studies which were conducted on other populations [10], [11], [16]. Furthermore, our data also pointed that the majority of cancer patients experienced that CAM therapy has no side effects. These findings are also well supported by other published studies [12], [13], [14]. Importantly, this study also investigated the experience of cancer patients for the usage of different CAM therapies, data pointed out that the majority of cancer patients experienced that herbal medicines/herbs were good for them as cancer therapy, however, similar number of patients also believed that different CAM in combined form were also good for their treatment, whereas some patients also experienced that homeopathic medicines were also good for their treatment. These findings have also been well supported by other studies on other cancer populations [10], [12]. To investigate more about the herbal therapies for cancer patients, experience of cancer patients was analyzed specifically for bran, plantain, green tea, black tea, capsicum, ginger, turmeric, black seeds, and fennel. Out of these herbal therapies, green tea and black seeds were found to be the favorable choice of cancer patients followed by the black tea, ginger turmeric, bran, plantain, fennel, and capsicum (Figure 3). In short, CAM therapies particularly consumption of green tea and black seeds for cancer patients proved to be a good alternative method besides the conventional chemotherapy.

\section{Conclusions}

To the best of our knowledge, this is the first comprehensive study from Saudi Arabia to show the experience of cancer patients for the usage of CAM therapies. In general, most of the cancer patients experienced that CAM therapies with the convention chemotherapy were effective for their treatment. Whereas, among all studied CAM therapies, green tea and black seeds were suggested by most of the patients for their cancer therapy. However, studies at both molecular and clinical levels are strongly recommended to show the true potential of CAM therapies for the treatment of cancer patients.

\section{Authors' Contributions}

All authors carried out data collection, interpretation and manuscript drafting. ZR and WA conceived of the study, its design, coordination, data interpretation, and manuscript drafting. All authors have read and approved the final manuscript.

\section{Availability of Data and Materials}

The data used in this study are available and will be provided by the corresponding author on a reasonable request.

\section{Acknowledgments}

The authors thank to the HIC program of Family and Communicate Medicine Department, College of Medicine, Qassim University, KSA. 


\section{Ethical Approval}

Ethical approval for this study was obtained from the Qassim University institutional review board.

\section{References}

1. Torre LA, Islami F, Siegel RL, Ward EM, Jemal A. Global cancer in women: Burden and trends. Cancer Epidemiol Biomarkers Prev. 2017;26(4):444-57. https://doi.org/10.1158/1055-9965. epi-16-0858

PMid:28223433

2. Torre LA, Siegel RL, Ward EM, Jemal A. Global cancer incidence and mortality rates and trends an update. Cancer Epidemiol Biomarkers Prev. 2016;25(1):16-27. https://doi. org/10.1158/1055-9965.epi-15-0578

PMid:26667886

3. Torre LA, Bray F, Siegel RL, Ferlay J, Lortet-Tieulent J, Jemal A. Global cancer statistics, 2012. CA Cancer J Clin. 2015;65(2):87108. https://doi.org/10.3322/caac.21262

PMid:25651787

4. Cresanta JL. Epidemiology of cancer in the United States. Prim Care. 1992;19(3):419-41.

PMid:1410056

5. Bazarbashi S, Al Eid H, Minguet J. Cancer incidence in Saudi Arabia: 2012 data from the Saudi cancer registry. Asian Pac J Cancer Prev. 2017;18(9):2437-44

PMid:28952273

6. Rudat V, Brune-Erbe I, Noureldin A, Bushnag Z, Almuraikhi N, Altuwaiji S. Epidemiology of breast cancer patients at a tertiary care center in the Eastern Province of Saudi Arabia. Gulf J Oncolog. 2012;11:45-9.

\section{PMid:22227545}

7. Herzallah HK, Antonisamy BR, Shafee MH, Al-Otaibi ST Temporal trends in the incidence and demographics of cancers, communicable diseases, and non-communicable diseases in Saudi Arabia over the last decade. Saudi Med J. 2019;40(3):27786. https://doi.org/10.15537/smj.2019.3.23585

PMid:30834424

8. Jabour AM, Dixon BE. Monitoring public health reporting: Data tracking in cancer registries. Online J Public Health Inform. 2018;10(3):e220. https://doi.org/10.5210/ojphi.v10i3.9432 PMid:30680053

9. Ernst $\mathrm{E}$. The role of complementary and alternative medicine. $\mathrm{Br}$ Med J. 2000;321:1133-5.

PMid:11061738

10. Molassiotis A, Fernández-Ortega P, Pud D, Ozden G, Scott JA Panteli V, et al. Use of complementary and alternative medicine in cancer patients: A European survey. Ann Oncol. 2005;16(4):655-63. https://doi.org/10.1093/annonc/mdi110 PMid:15699021

11. Ernst E, Cassileth BR. The prevalence of complementary/ alternative medicine in cancer. A systematic review. Cancer. 1998;83(4):777-82. https://doi.org/10.1002/ (sici)1097-0142(19980815)83:4<777::aid-cncr22>3.0.co;2-o PMid:9708945

12. Niggemann B, Gruber C. Side-effects of complementary and alternative medicine. Allergy. 2003:58(8):707-16. https://doi. org/10.1034/j.1398-9995.2003.00219.x

\section{PMid:12859546}

13. Richardson MA, Sanders $T$, Palmer JL, Greisinger A Singletary SE. Complementary/alternative medicine use in a comprehensive cancer center and the implications for oncology. J Clin Oncol. 2000;18(13):2505-14. https://doi.org/10.1200/ jco.2000.18.13.2505

PMid: 10893280

14. Oneschuk D, Fennell L, Hanson J, Bruera E. The use of complementary medications by cancer patients attending an outpatient pain and symptom clinic. J Palliat Care. 1998;14(4):21-6. https://doi.org/10.1177/082585979801400404 PMid:9893394

15. Bernstein BJ, Grasso T. Prevalence of complementary and alternative medicine use in cancer patients. Oncology. 2001;15(10):1267-72.

PMid:11702957

16. Sparber A, Bauer L, Curt G, Eisenberg D, Levin T, Parks S, et al Use of complementary medicine by adult patients participating in cancer clinical trials. Oncol Nurs Forum. 2000;27:623-30. t https://doi.org/10.1097/01893697-200119020-00031 PMid: 10833691

17. Swisher EM, Cohn DE, Goff BA, Parham J, Herzog TJ, Rader JS, et al. Use of complementary and alternative medicine among women with gynecologic cancers. Gynecol Oncol. 2002;84(3):363-7. https://doi.org/10.1006/gyno.2001.6515 PMid: 11855870

18. Von Gruenigen VE, White LJ, Kirven MS, Showalter AL, Hopkins MP, Jenison EL. A comparison of complementary and alternative medicine use by gynecology and gynecologic oncology patients. Int J Gynecol Cancer. 2001;11:205-9. https:// doi.org/10.1046/j.1525-1438.2001.01011.x PMid:11437926

19. Bennett $M$, Lengacher $C$. Use of complementary therapies in a rural cancer population. Oncol Nurs Forum. 1999;26:1287-94. PMid:10497768

20. Siegel RL, Miller KD, Jemal A. Cancer statistics, 2019. CA Cancer J Clin. 2019;69(1):7-34. PMid:30620402

21. Shah SC, Kayamba V, Peek RM Jr., Heimburger D. Cancer control in low- and middle-income countries: Is it time to consider screening? J Glob Oncol. 2019;5:1-8. https://doi.org/10.1200/ jgo. 18.00200

PMid:30908147

22. Cialdella-Kam L, Sabado P, Bispeck MK, Silverman S, Bernstein L, Krawiec V, et al. Implementing cancer prevention into clinical practice. J Cancer Educ. 2012;27(Suppl 2):S136-43. https://doi.org/10.1007/s13187-012-0331-6 PMid:22367592

23. Jazieh AR, AIGhamdi M, AIGhanem S, AIGarni M, AlKattan K, AIRujaib $M$, et al. Saudi lung cancer prevention and screening guidelines. Ann Thorac Med. 2018;13(4):198-204. https://doi. org/10.4103/atm.atm_147_18 PMid:30416590

24. Meyskens FL Jr., Mukhtar H, Rock CL, Cuzick J, Kensler TW, Yang CS, et al. Cancer prevention: Obstacles, challenges and the road ahead. J Natl Cancer Inst. 2015;108(2):djv309. https:// doi.org/10.1093/jnci/djv309

PMid:26547931

25. Devlin EJ, Denson LA, Whitford HS. Cancer treatment side effects: A meta-analysis of the relationship between response expectancies and experience. J Pain Symptom Manage 2017;54(2):245-58. https://doi.org/10.1016/j. jpainsymman.2017.03.017

PMid:28533160 
26. Wode K, Henriksson R, Sharp L, Stoltenberg A, Hok Nordberg J. Cancer patients' use of complementary and alternative medicine in Sweden: A cross-sectional study. BMC Complement Altern Med. 2019;19(1):62. https://doi.org/10.1186/s12906-019-2452-5 PMid:30866916

27. Rasheed Z. Molecular evidences of health benefits of drinking black tea. Int J Health Sci (Qassim). 2019;13(3):1-3. PMid:31123432

28. Rasheed Z. Medicinal values of bioactive constituents of camel milk: A concise report. Int J Health Sci (Qassim). 2017;11(5):1-2. PMid:29114185

29. Rasheed Z. Green tea bioactive polyphenol epigallocatechin3-O-Gallate in osteoarthritis: Current status and future perspectives. Int J Health Sci (Qassim). 2016;10(4):5-8. https:// doi.org/10.12816/0048888

30. Rasheed Z, Rasheed N, Al-Shaya O. Epigallocatechin-3-Ogallate modulates global microRNA expression in interleukin$1 \beta$-stimulated human osteoarthritis chondrocytes: potential role of EGCG on negative co-regulation of microRNA-140-3p and ADAMTS5. Eur J Nutr. 2018;57(3):917-28. https://doi. org/10.1007/s00394-016-1375-x

PMid:28110479

31. Rasheed Z, Altorbag AA, Al-Bossier AS, Alnasser NA, Alkharraz OS, Altuwayjiri KM, et al. Protective potential of thymoquinone against peroxynitrite induced modifications in histone H2A: In vitro studies. Int J Biol Macromol. 2018;112:16974. https://doi.org/10.1016/j.ijbiomac.2018.01.157 PMid:29414727

32. Rasheed Z, Rasheed N, Al-Shobaili HA. Epigallocatechin3-O-gallate up-regulates microRNA-199a-3p expression by down-regulating the expression of cyclooxygenase-2 in stimulated human osteoarthritis chondrocytes. J Cell Mol Med. 2016;20(12):2241-8. https://doi.org/10.1111/jcmm.12897 PMid:27515563

33. Rasheed Z. Intake of pomegranate prevents the onset of osteoarthritis: Molecular evidences. Int J Health Sci (Qassim). 2016;10(2):5-8. https://doi.org/10.12816/0048807

34. Rasheed N, Alghasham A, Rasheed Z. Lactoferrin from Camelus dromedarius inhibits nuclear transcription factor-kappa B activation, cyclooxygenase-2 expression and prostaglandin $\mathrm{E}_{2}$ production in stimulated human chondrocytes. Pharmacogn Res. 2016;8(2):135-41. https://doi.org/10.4103/0974-8490.175612

\section{PMid:27034605}

35. Rasheed Z, Akhtar N, Haqqi TM. Pomegranate extract inhibits the interleukin-1 $\beta$-induced activation of MKK-3, p38 $\alpha$-MAPK and transcription factor RUNX-2 in human osteoarthritis chondrocytes. Arthritis Res Ther. 2010;12(5):R195. https://doi. org/10.1186/ar3166

PMid:20955562

36. Rasheed Z, Akhtar N, Khan A, Khan KA, Haqqi TM. Butrin, isobutrin, and butein from medicinal plant Butea monosperma selectively inhibit nuclear factor-kappaB in activated human mast cells: Suppression of tumor necrosis factor-alpha, interleukin (IL)-6, and IL-8. J Pharmacol Exp Ther. 2010;333(2):354-63. https://doi.org/10.1124/jpet.109.165209

PMid:20164300

37. Rasheed Z, Anbazhagan AN, Akhtar N, Ramamurthy S, Voss FR, Haqqi TM. Green tea polyphenol epigallocatechin-3-gallate inhibits advanced glycation end product-induced expression of tumor necrosis factor-alpha and matrix metalloproteinase-13 in human chondrocytes. Arthritis Res Ther. 2009;11(3):R71. https://doi.org/10.1186/ar2700

\section{PMid:19445683}

38. Rasheed Z, Akhtar N, Anbazhagan AN, Ramamurthy S, Shukla M, Haqqi TM. Polyphenol-rich pomegranate fruit extract (POMx) suppresses PMACl-induced expression of pro-inflammatory cytokines by inhibiting the activation of MAP Kinases and NF-kappaB in human KU812 cells. J Inflamm (Lond). 2009;6:1. https://doi.org/10.1186/1476-9255-6-1

PMid: 19133134

39. Shukla M, Gupta K, Rasheed Z, Khan KA, Haqqi TM. Bioavailable constituents/metabolites of pomegranate (Punica granatum $\mathrm{L}$ ) preferentially inhibit $\mathrm{COX}_{2}$ activity ex vivo and IL-1 beta-induced $\mathrm{PGE}_{2}$ production in human chondrocytes in vitro. J Inflamm (Lond). 2008;5:9. https://doi.org/10.1186/1476-9255-5-9 PMid: 18554383

40. Shukla M, Gupta K, Rasheed Z, Khan KA, Haqqi TM. Consumption of hydrolyzable tannins-rich pomegranate extract suppresses inflammation and joint damage in rheumatoid arthritis. Nutrition. 2008;24(7-8):733-43. https://doi. org/10.1016/j.nut.2008.03.013

PMid: 18490140 